\title{
ORGANIZATIONAL COMMITMENT, JOB INSECURITY AND JOB INVOLVEMENT AND MEDIATION EFFECTS OF POSITIVE EMOTION
}

\author{
Li Zhang \\ Siam University, Bangkok, Thailand \\ Liou-Yuan Li \\ Rajamangala University of Technology Thanyaburi, Thailand \\ Jidapa Chollathanrattanapong \\ Guang-Lei Lu \\ Siam University, Bangkok, Thailand
}

This study aimed to investigate the effects of job insecurity on organizational commitment and Job Involvement respectively and the mediation effects of positive emotion thereto. The

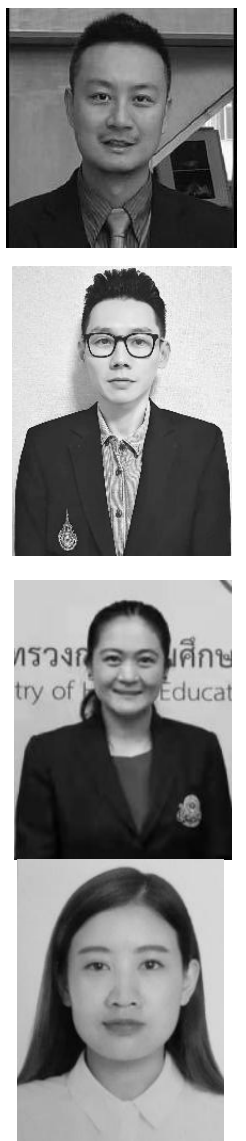

\section{Li Zhang}

Dr., Assistant President, Siam University, Bangkok, Thailand.

Research Interests: Human resource management

Email: lizhang@siam.edu

Liou-Yuan Li

Dr., Lecturer, Faculty of Business Administration,

Rajamangala University of Technology Thanyaburi, Thailand.

Research Interests: organization behavior

Email: liou_y@rmutt.ac.th

\section{Jidapa Chollathanrattanapong}

Lecturer, International college, Siam University, Bangkok, Thailand.

Research Interests:education management

Email: siamzhu@gmail.com

\section{Guang-Lei Lu}

Lecturer, International college, Siam University, Bangkok, Thailand.

Research Interests: marketing management

Email: guanglei.lu@siam.edu 


\section{ORGANIZATIONAL COMMITMENT, JOB INSECURITY}

hypotheses this research addressed are (1) Job insecurity has no significant effect on organizational commitment; (2) Job insecurity has a significant negative effect on Job Involvement; (3) Organizational commitment has a significant positive effect on Job Involvement. (4) Positive emotion failed to reduce the negative effect of job insecurity on organizational commitment and Job Involvement respectively. The results show that, the powerlessness in job insecurity is a key factor affecting organizational commitment and Job Involvement. And the powerlessness in job insecurity not only affects organizational commitment and Job Involvement but also affects Job Involvement through organizational commitment.

Keywords: job insecurity; job involvement; positive emotion; organizational commitment

\section{Introduction}

From the financial crisis of 2008 to the current Covid-19 epidemic, Taiwan's economy and labor market suffered a huge impact by the global economic and financial turbulences. Not only enterprises faced big challenges at any time, but also employees suffered the risk of losing their jobs at any time. If an enterprise is a human body, employees are all its organs. The human body cannot perform its functions without well-cared healthy organs. Therefore, job insecurity is an issue that enterprises should pay attention to.

In the environment of well-developed network, current enterprises are facing the challenge of rapid elimination. In order to maintain their competitiveness, business managers are sparing no efforts to improve profits and reduce cost. As a result, it is common to hear about downsizing of enterprises such as restructuring or recruitment (Sanghamitra \& Leena, 2005), and these reform measures often made the internal employees of the organization generate job insecurity to their current work environment (Prashant et al., 2004).

Insecurity is the anxiety and negative emotion generated when the information received is psychologically uncontrollable or an objective threat is perceived (Dewitte, 1989). When such negative emotion is generated, the work-relevant attitudes of employees can be easily affected, for example, the work satisfaction is lowered due to reduced organizational commitment, or employee's turnover intention is generated (Ashford et al., 1989).

Job Involvement occurs when a job meets an individual's expectations and needs (Kanungo, 1982). When an individual has a sense of job insecurity, it will have a negative impact on the level of Job Involvement and organizational commitment, which further impacts employee performance.

Organizational commitment and Job Involvement are important indicators to measure the performance of employees, and the development of enterprise depends on the working attitude and performance of the employees within the organization. As a result, the organizational commitment and Job Involvement are playing a significant role. Although some scholars hold that job insecurity may increase Job Involvement and devotion, most studies found that job insecurity lowered Job Involvement. It is believed that managers can lower job insecurity and the negative pressure of employees through positive incentive means, making employees contribute their talents in pleasant working environment, thus obtaining the Job Involvement and organizational commitment of excellent staff.

Emotion is an emotional response of the individual, so the impact of job insecurity on organizational commitment and Job Involvement may vary based on the emotional state of 
the individual. Managers must recognize the basic fact that not only do employees have different traits from each other, but even employees themselves may have different behaviors or psychological reactions from the past due to the influence of environment, family, or work. Therefore, the enterprise managers should really understand and care about the real thoughts and feelings of employees. This is also the purpose of this study to explore the effects of job insecurity and employee emotional traits on Job Involvement and organizational commitment through scientific objective methods. Therefore, this study has three targets:

1. To explore the impact of job insecurity on Job Involvement and organizational commitment

2. To explore the impact of organizational commitment on Job Involvement

3. To explore whether emotional experience mediates the impact of job insecurity on Job Involvement and organizational commitment

\section{Literature Review}

Job insecurity can be defined as the feeling of pressure that an individual feels when he or she is in an objectively threatening work environment and the uncertain situation cannot be changed after subjective cognition. Therefore, there are three dimensions for job insecurity, namely

1. Objectively threatening work environment;

2. Personal subjective cognition;

3. Powerlessness.

Ashford et al. (1989) analyzed job insecurity in the formula as below:

1. (threatening feeling of change in job characteristics) $=$ (significance of job characteristic) $\mathrm{x}$ (possibility of change in job characteristics)

2. $($ threatening feeling of job change $)=($ significance of job change $) \times$ (possibility of job change)

3. [(threatening feeling of change in job characteristics) + (threatening feeling of job change) $\mathrm{X}$ (powerlessness) $=$ (job insecurity).

This definition incorporated the complete dimensions of job insecurity.

Therefore, this study adopted the definition of job insecurity by Ashford et al. (1989). What are the reasons for job insecurity of employees? According to the above formula, the reasons respectively are the threatening feeling of job change such as corporate merger, sales, decruitment, downsizing, restructuring and other organizational factors, threatening feeling of change in job characteristics such as technical change and other work conditions, and the feeling of powerlessness such as health, work pressure, career crisis and other personal cognitive factors (Ashford et al., 1989; Borgatta et al., 1968; Greenhalgh \& Rosenblatt, 1984).

These reasons may cause negative emotions to employees. Job insecurity has another big impact, namely that it increases work pressure and has a negative impact on health or increases turnover intention of employees. Cooper et al. (2001) maintain that job insecurity is one of the sources for work pressure, and Greenhalgh \& Rosebaltt (1984) hold that job insecurity may lead to turnover intention of employees.

Meyer et al. (1991) divided organizational commitment into three dimensions, namely affective, continuance normative commitments. Affective commitment refers to an 


\section{ORGANIZATIONAL COMMITMENT, JOB INSECURITY}

individual's psychological or emotional attachment to and commitment to an organization, while continuance commitment is an individual's willingness to stay in the organization after economic benefit and invested cost considerations. Finally, normative commitment means that employees hold that loyalty to the organization is a value that needs to be obeyed absolutely due to social experience. Therefore, this study adopted the definition of organizational commitment by Meyer et al. (1991).

Does hard work mean job involvement? The word "job involvement" was proposed by Lodahl \& Kejner (1965), who defined it as the degree of personal identification with work or the importance of work in the self-impression, namely that the more an individual identifies with his work or the higher the status of work in the self-impression, the higher the job involvement will be. In addition, job involvement is also affected by the correlation between self-esteem and personal performance at work. The stronger the correlation between job performance and self-esteem, the higher the job involvement will be.

The above definition found that the formation of organizational commitment is an individual's attachment to the emotion and interest relationship of the organization, which is a positive attitude of the individual towards the relationship of the organization. However, when the negative emotion of job insecurity occurs in the mind of the employee, will such a positive attachment relationship be damaged?

Sverke et al. (2002) studies noted that after organization downsizing is implemented, the job insecurity of the remaining employees will increase, and the organizational commitment and trust in the organization will gradually decrease. In addition, Sverke et al. (2002) also found that the formation of job insecurity decreases organizational commitment. Therefore, this study re-verified the relationship between the two variables, thus proposing the hypotheses as below:

\section{Hypothesis 1: Job insecurity has a significant negative effect on organizational commitment}

Rosenblatt \& Ruvio (1996) studies found that the formation of job insecurity has an impact on job involvement of employees. Kuhert \& Palmer (1991) conducted a study on part-time and full-time employees, and this study found that job insecurity had a significant negative effect on job involvement, even though most studies found that job insecurity caused by different types of employees has different effects on job involvement.

However, such different effects must have been affected by mediation variables. This study is to control these mediation effects. Therefore, this study is to re-verify the relationship between two variables, thus proposing the hypotheses as below:

\section{Hypothesis 2: Job insecurity had a significant negative effect on job involvement}

Steers (1977) pointed out that organizational commitment has multiple functions, in which members with high organizational commitment have higher job involvement. Mathieu\& Zajac (1990) studies indicated that the better the working conditions, the more willing employees are to make contributions to the organization and effectively establish intimate relationships, thus improving organizational commitment and facilitating the promotion of employees' job involvement.

Clinebell \& Shadwick (2005) studies also found that employees' trust and dependence on the organization produce organizational commitment, which has the effect of increasing job involvement. 
This study held that organizational commitment generally includes employees' compliance with the norms, emotional identification and the continuance of interest relations, while job involvement is limited to the degree of job identification and dedication. Therefore, organizational commitment should have a significant positive impact on job involvement. Therefore, the following hypotheses are proposed in this study:

\section{Hypothesis 3: Organizational commitment has a significant positive effect on job involvement}

According to hypothesis 1: job insecurity has a significant negative effect on organizational commitment and hypothesis 3: organizational commitment has a significant positive effect on job involvement, it can be deducted in hypothesis 4 that job insecurity has a significant negative effect on job involvement through organizational commitment.

Ellis (1979) held that emotion is a complex state after the integration of human behavior reaction and perception, that is, a state of cognition-perception. Brave \& Nass (2003) proposed that emotion is the response to personal goals and needs or concerns, which includes physiological, emotion, behavior and cognition.

Therefore, it can be known that emotion is a response triggered by the stimulation of external factors, such as the environment and the behavior of others, and there will be different types or degrees of response due to different cognitions of individuals.

The literate showed that individuals with positive emotional traits have a strong ability to adjust to negative emotions, positive emotions can also eliminate the original negative emotions, and the experience of cultivating positive emotions can improve the response to negative emotions Fredrickson (2002).

In addition, according to Folkman \& Moskowiz (2000), the tension of the individual in the stress can be reduced through positive emotion, including positive re-evaluation, problem-oriented solution and granting optimistic meaning to the occurrence of events. The above study results showed that job insecurity is also a kind of negative emotions, which is an individual's feeling of stress and anxiety and then shows a negative impact on organizational commitment and job involvement.

From another point of view, individuals can be motivated to perform better at work through benign stress. However, most of the effects of stress and anxiety on individuals are negative, and excessive stress is more likely to cause physical discomfort. The individual's response to pressure often varies due to the individual's different feeling degrees of pressure or frustration tolerances. Whether employees with positive emotional traits can reduce the negative effect of job insecurity and then rethink the correct actions to take for their jobs and organizations. For enterprises, whether employees have positive emotional traits should also have a mediation effect on the impact of job insecurity. Therefore, this study proposed the hypotheses as below:

Hypothesis 5: Positive emotion mediates and reduces the negative effect of job insecurity on organizational commitment

Hypothesis 6: Positive emotion mediates and reduces the negative effect of job insecurity on job involvement 


\section{ORGANIZATIONAL COMMITMENT, JOB INSECURITY}

\section{Research method}

The questionnaires were distributed to full-time workers in the private sector, as employees in the public sector or organizations have more job security and less job insecurity. A total of 400 valid questionnaires were distributed, and 400 valid questionnaires were collected. The questionnaires were numbered, archived and analyzed using SPSS software.

According to the Job Insecurity Scale proposed by Ashford et al. (1989), there were 57 questions in total. Analysis results showed that the Cranach's $\alpha$ in the Job Insecurity Scale is 0.835 , and the reliability coefficient is within a good range, indicating that the scale has internal consistency.

However, the huge number of questions may affect the willingness and correctness of the subjects, and most researchers use the narrow sense of job insecurity such as job loss, as the measurement basis of job insecurity. Considering this fact, this study adopted the Job Insecurity Questionnaire proposed by Ashford et al. (1989), which included threat of job loss and perceived powerlessness to counter the threat (the threat of change in job feature has been eliminated).

"Degree of concern after job loss", which integrated the likelihood of job loss and the importance of job loss originated from the threatening feeling of job loss, was measured as a job insecurity questionnaire, so as to improve the willingness of participants to fill in the questionnaire. Likert 5-point scale was used in the questionnaire statistics, and finally the overall job insecurity score was calculated according to the following formula.

"Occurrence of job loss and degree of concern" namely "threatening feeling of job loss", multiplied by "the perceived powerlessness" to counter the threat $=$ "the job insecurity".

The study adopted the Three-Construct Organizational Commitment Questionnaire. After reliability testing, the questions with low reliability were deleted, the reliability of each construct was between 0.791 to 0.808 , and the entire-construct reliability reached 0.857 .

\section{Job Involvement}

This scale had three constructs: vigor, dedication and absorption. Each construct had three questions using Likert Type 7-point scale for scoring. Participants answered the questions according to their actual situations, and the coefficient of internal consistency (Cronbach $\alpha$ ) was 0.942 .

The coefficient of internal consistency (Cronbach $\alpha$ ) in this scale reached 0.93 , and the reliability of each construct of the scale rose from 0.86 to 0.92 , indicating that this scale has a high level of reliability.

\section{Research Results}

Reliability analysis-This study adopted the Cronbach $\alpha$ coefficient to test the consistency between the constructs of the questionnaire, see Tab. 1 for research results. In the job insecurity construct, the threatening feeling of job loss and the powerlessness to counter the threat were tested for consistency respectively. 
Table 1 - Reliabilities of Scales

(source: authors' calculations)

\begin{tabular}{|l|c|c|}
\hline \multicolumn{1}{|c|}{ Scale } & Options & Cronbach $\alpha$ \\
\hline Job Insecurities & $1 \sim 13$ & 0.88 \\
\hline -Threatening feeling of job loss & $1 \sim 10$ & 0.92 \\
\hline -Powerlessness to counter the threat & $11 \sim 13$ & 0.82 \\
\hline Organizational commitment & $1 \sim 15$ & 0.76 \\
\hline Job involvement & $1 \sim 9$ & 0.95 \\
\hline Positive emotion & $1 \sim 19$ & 0.82 \\
\hline
\end{tabular}

Correlation analysis-Correlation analysis is to study the correlation between the variables in the research framework, a positive value indicating a positive correlation, a negative value indicating a negative correlation.

See Tab. 2 for the variables of this study such as population statistics, job insecurity, organizational commitment, job involvement and positive emotion:

This study tested the correlation between the two variables in the research framework by Pearson Correlation Coefficient.

It can be known from Tab. 1 that marriage is positively correlated with organizational commitment $(\mathrm{r}=.20, \mathrm{p}<.01)$; education is negatively correlated with organizational commitment $(\mathrm{r}=-.16, \mathrm{p}<.05)$; the supervisor-level position is positively correlated with organizational commitment and job involvement but is negatively correlated with job insecurity $(\mathrm{r}=.20, \mathrm{p}<.01 ; \mathrm{r}=.16, \mathrm{p}<.05 ; \mathrm{r}=-.20, \mathrm{p}<.01)$, namely that a married participant had a higher organizational commitment and a participant with high educational level had a lower organizational commitment.

The supervisor-level participant had a higher organizational commitment and job involvement but had a lower job insecurity.

However, among the measured variables, job insecurity showed a significant negative correlation with

-job involvement and positive emotion ( $\mathrm{r}=-.35, \mathrm{p}<.01 ; \mathrm{r}=-.36, \mathrm{p}<.01)$;

-organizational commitment showed a significant positive correlation with job involvement and positive emotion $(\mathrm{r}=.45, \mathrm{p}<.01 ; \mathrm{r}=.25, \mathrm{p}<.01)$;

-job involvement showed a significant positive correlation with positive emotion $(\mathrm{r}=.51, \mathrm{p}<.01)$,

and only the job insecurity showed a negative correlation with organizational commitment $(r=-.02 ; p>.5)$ but the correlation was not significant. In the analysis of common method deviation problem, the analysis results were divided into 10 factors, the maximum explicable variation was $26.994 \%$, and no common method deviation problem occurred. 
Table 2 - Correlation Analysis (source: authors' calculations)

\begin{tabular}{|c|c|c|c|c|c|c|c|c|c|c|c|c|c|}
\hline & $\begin{array}{l}\text { Z } \\
\text { 这 } \\
\sum\end{array}$ & ถิ & $\ll$ & $\sim$ & U & D & 피 & L & ט & $I$ & - & $\neg$ & 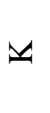 \\
\hline $\operatorname{Age}(B)$ & & & 0 & & & & & & & & & & \\
\hline $\begin{array}{l}\text { Marriage } \\
\text { (C) }\end{array}$ & & & $\stackrel{*}{\leftrightharpoons}$ & 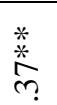 & & & & & & & & & \\
\hline $\begin{array}{l}\text { Education } \\
\text { (D) }\end{array}$ & & & $\stackrel{*}{\stackrel{*}{*}}$ & $\stackrel{0}{\stackrel{1}{1}}$ & $\underset{i}{\stackrel{0}{0}}$ & & & & & & & & \\
\hline $\begin{array}{l}\text { Tenure } \\
\text { (E) }\end{array}$ & & & $\bar{\sigma}_{i}$ & ติ & $\begin{array}{l}* \\
* \\
m\end{array}$ & $\stackrel{\infty}{0}$ & & & & & & & \\
\hline $\begin{array}{l}\text { Position } \\
\text { (F) }\end{array}$ & & & $\frac{*}{\stackrel{*}{*}}$ & $\frac{*}{\stackrel{*}{m}}$ & $\stackrel{*}{\stackrel{*}{h}}$ & 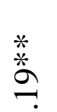 & 莡 & & & & & & \\
\hline $\begin{array}{l}\text { Industry } \\
\text { (G) }\end{array}$ & & & $\stackrel{0}{?}$ & $\stackrel{m}{\rightarrow}$ & os & $\stackrel{ \pm}{ت}$ & O̦ & $\stackrel{m}{?}$ & & & & & \\
\hline $\begin{array}{l}\text { Job insecurity } \\
\text { (H) }\end{array}$ & 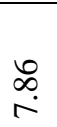 & $\underset{\dot{r}}{\vec{r}}$ & 8 & $g_{i}$ & $\sigma_{i}$ & $\exists_{i}$ & $\hat{\delta}$ & \begin{tabular}{l}
$*$ \\
$*$ \\
\multirow{2}{*}{}
\end{tabular} & $=$ & & & & \\
\hline $\begin{array}{l}\text { Organizational } \\
\text { commitment } \\
\text { (I) }\end{array}$ & $\frac{I}{m}$ & $\stackrel{\infty}{n}$ & $e_{i}$ & \&. & 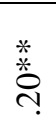 & $\stackrel{*}{\stackrel{*}{*}}$ & $\stackrel{m}{\longrightarrow}$ & 峃 & $=$ & $\delta_{i}$ & & & \\
\hline $\begin{array}{l}\text { Job involve- } \\
\text { ment }(\mathrm{J})\end{array}$ & $\stackrel{\substack{++}}{ }$ & $\stackrel{\sigma}{\sigma}$ & $\underbrace{t}_{i}$ & $\underbrace{}_{i}$ & ô. & $\hat{\theta}_{i}$ & o. & 晜 & \&. & $\begin{array}{l}* \\
\stackrel{*}{*} \\
n \\
i\end{array}$ & $\begin{array}{l}* \\
* \\
\text { * }\end{array}$ & & \\
\hline $\begin{array}{l}\text { Positive emotion } \\
\text { (K) }\end{array}$ & ஸે & ஸे? & రิ & $\stackrel{\infty}{\underset{i}{0}}$ & \&. & $\stackrel{8}{0}$ & $\ell_{i}$ & $\varnothing_{i}$ & $\overline{0}$ & \begin{tabular}{l}
$*$ \\
$\stackrel{*}{*}$ \\
\multirow{2}{*}{}
\end{tabular} & 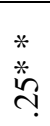 & $\begin{array}{l}* \\
\text { * } \\
\stackrel{*}{n}\end{array}$ & \\
\hline
\end{tabular}

$* * \mathrm{P}<\mathrm{p}<.01 * \mathrm{p}<.05$ (The mean and standard deviation are not calculated because the survey is conducted in the range of age and tenure.)

\section{Regression Analysis of Variables}

In order to further explore the significant correlation between job insecurity, organizational commitment and job involvement, this section adopted the hierarchical regression analysis method, used gender, age, marriage, education, tenure, supervisor-level title and industry as control variables, and then added positive emotion as an extraneous 
variable to analyze the interaction effect between the variables. Analysis results showed that the marriage and job title in the population statistics variable had a significant positive effect on organizational commitment $(\beta=0.182, \mathrm{t}=2.487, \mathrm{P}=.014<0.05 ; \quad \beta=0.242, \mathrm{t}=3.282$, $\mathrm{P}=.001<0.01$ ), indicating that married or supervisor-level employees had a higher organizational commitment while the degree of education had a negative effect on organizational commitment $(\beta=-0.193, \mathrm{t}=-2.724, \mathrm{P}=.007<0.05)$, that is to say, the higher the degree of education is, the lower the organizational commitment will be.

The results of hypothesis 1 was obtained that job insecurity had no significant negative effect on organizational commitment $(\beta=-0.016, \mathrm{t}=-.234, \mathrm{~F}=3.785, \mathrm{P}=.815>0.05)$, therefore hypothesis 1: job insecurity had a significant negative effect on organizational commitment was false. According to hypothesis 1, the hypothesis 4: job insecurity had a significant negative effect on job involvement through organizational commitment was false, and the hypothesis 5: positive emotion mediated and reduced the negative effect of job insecurity on organizational commitment was also false.

In order to test the associations between job insecurity, job involvement and positive emotion, research results also found that the job title in the population statistics variable had a significant positive effect on job involvement $(\beta=0.229, \mathrm{t}=-2.970, \mathrm{P}=.003<0.05)$, namely that supervisor-level employees had a higher job involvement; job insecurity had a significant negative effect on job involvement $(\beta=-0.344, \mathrm{t}=-5.086, \mathrm{P}=.000<0.001)$, namely that job insecurity had a significant negative effect on job involvement. The higher the job insecurity is, the lower the job involvement was, that is to say, the hypothesis 2: job insecurity had a significant negative effect on job involvement was true.

In the process of studying whether positive emotion mediated the negative effect of job insecurity on job involvement, the collinearity statistic VIF value was 10.323 , which was a collinearity problem. Therefore, the population statistic variable, independent variable, dependent variable and mediation variable were standardized, and then the new $\beta=-0.074$, $\mathrm{t}=-1.095$, and VIF value was 1.069 , which had no collinearity problem and also had no significant effect. Therefore, the hypothesis 6: positive emotion mediated and reduced the negative effect of job insecurity on job involvement was also false.

Research results showed that organizational commitment had a significant positive effect on job involvement $(\beta=0.466, \mathrm{t}=6.904, \mathrm{P}=.000<0.001)$, namely that hypothesis 3 : organizational commitment had a significant positive effect on job involvement was true.

This study adopted the Job Insecurity Questionnaire proposed by Ashford et al. (1989), which included the threatening feeling of job loss and the perceived powerlessness to counter the threat. The factor analysis was conducted for the Job Insecurity Questionnaire Scale. KMO value was 0.847 , which was higher than 0.8 , indicating that the factor analysis can be performed.

Analysis results showed that the factor analysis can be divided into 3 constructs, in which the threatening feeling of job loss can be further divided into loss of job itself and loss of job features as two constructs, and the third construct was to measure the powerlessness to counter the job insecurity.

The absolute value of the factor load of the questions after rotation axis was all larger than 0.5 , the cumulative explicable variation was $73.84 \%$, and the component characteristic value of the three constructs was all larger than 1, indicating that the factor structure was benign. 


\section{ORGANIZATIONAL COMMITMENT, JOB INSECURITY}

This questionnaire divided job insecurity into the threatening feeling of job loss and the powerlessness to counter the threat, and further analyzed the effects thereof on organizational commitment. The analysis results discovered that the powerlessness to counter the threatening feeling of job loss had a significant negative effect on organizational commitment $(\beta=-0.209, \mathrm{t}=-3.107, \mathrm{~F}=5.173, \mathrm{P}=.002<0.01)$. Therefore, it can be known that the higher the perceived powerlessness is, the lower the organizational commitment will be, indicating that the job insecurity had an effect was true.

Examinations were made about whether positive emotions can mediate the negative effect of powerlessness on organizational commitment. The results found that positive emotions mediated the negative effect of powerlessness on organizational commitment $(\beta=0.260, t=2.041, \mathrm{~F}=5.137, \mathrm{P}=.043<0.05)$. Therefore, powerlessness had a negative effect on organizational commitment, and positive emotions mediated such negative effect. As a result, hypothesis 1 and hypothesis 5 were partially true.

It was not possible to analyze whether positive emotions mediated and reduced the negative effect of job insecurity on job involvement due to the collinearity problem. However, this section reanalyzed whether positive emotions mediated the effect of powerlessness on job involvement. The analysis results found that powerlessness had a negative effect on job involvement $(\beta=-0.402, \mathrm{t}=-6.088, \mathrm{P}=.000<0.001)$ and positive emotions mediated the negative effect of powerlessness on job involvement $(\beta=0.680$, $\mathrm{t}=5.853, \mathrm{P}=.000<0.001)$.

However, the collinearity test concluded that VIF value was 3.851, the collinearity was still high, and therefore, the variable analysis results after standardization showed that $\beta=0.021, \mathrm{t}=0.321$, and VIF value was 1.038 .

There was no collinearity problem, but the mediation effect was not significant.

Although hypothesis 4: job insecurity had a significant negative effect on job involvement through organizational commitment was false, the powerlessness in the job insecurity had a significant effect on organizational commitment $(\beta=-0.209, \mathrm{t}=-3.107$, $\mathrm{F}=5.173, \mathrm{P}=.002<0.01$ ), and organizational commitment had a significant effect on job involvement $(\beta=0.466, \mathrm{t}=6.904, \mathrm{P}=.000<0.001)$.

In addition, this study examined whether powerlessness affected job involvement through organizational commitment by regression analysis and structural equation modeling (SEM).

It examined and deducted the direction relationship and mediation effect between the variables by regression model, and then analyzed the concrete relationship between the variables.

According to the method above, three conditions must be met to examine whether variables had mediation effect by regression analysis:

1.Independent variable and mediation variable must have a significant relationship with dependent variable respectively and separately.

2.Independent variable must have a significant relationship with mediation variable.

3.After mediation variable was added into the regression formula of independent variable and dependent variable, the effects of independent variable, which used to be significant, changed to insignificant, concluding that the mediation variable had full mediation effects; if the effects of the independent variable, which used to be significant, were still significant, concluding that the mediation variable had partial mediation effects, and the independent variable had both direct and indirect relationship with the dependent 
variable. This study examined the mediation effects in hypothesis 4 according to the above steps, which examined the relationship between powerlessness, organizational commitment and job involvement.

The analysis results were as below, in which both powerlessness and organizational commitment had a significant relationship with job involvement $(\beta=-0.42$, $\mathrm{P}=.000<0.001 ; \beta=0.46, \mathrm{P}=.000<0.001)$, therefore, the condition 1 was met, and the condition 2 was also met, namely that the powerlessness also had a significant relationship with organizational commitment $(\beta=-0.25, \mathrm{P}=.000<0.001)$; finally the organizational commitment was added into the regression model of powerlessness and job involvement $(\beta=-$ $0.38, \mathrm{P}=.000<0.001$ ), and the results found that the significant effect of powerlessness on job involvement still existed but the degree of significance decreased $(\beta=-0.33, P=.000<0.001), \beta$ value decreased from -0.42 to -0.33 , concluding that the partial mediation effects in the condition 3 were met.

It can be confirmed that the powerlessness had a direct impact on job involvement and also had an indirect impact on organizational commitment, which further produced an indirect impact on job involvement.

\section{Conclusion}

This study found that only the hypotheses 2 and 3 were true and that the hypotheses 1 , 4, 5 and 6 were not supported. Therefore, job insecurity had no significant negative effect on organizational commitment, that is to say, job insecurity had no significant relationship with organizational commitment.

However, job insecurity had a significant negative effect on job involvement, which conformed to the results concluded by most researchers such as Kuhert \& Palmer (1991) and Rosenblatt \& Ruvio (1996). Job insecurity was a kind of negative emotion, and job involvement required positive emotions. Therefore, it can be deducted that when employees have internal negative emotional interference, the positive emotions of job involvement will be reduced. The effect of organizational commitment on job involvement was consistent with the research results of most researchers such as Mathieu \& Zajac (1990) and Clinebell \& Shadwick (2005), indicating that organizational commitment had a significant positive effect on job involvement.

In this study, positive emotion failed to become an effective mediation variable. The level of the impact of negative emotions may be reduced through positive emotions. However, when employees had feelings of job insecurity, positive emotions may reduce some of the inner impact of employees, but it still cannot change the negative impact of job insecurity on job involvement. That is to say, in terms of job insecurity, employees with positive emotions may reduce some impact on their own psychological and health status, but they still cannot effectively improve the negative impact on organizational commitment and job involvement.

The results of this study found that job insecurity had no significant negative effect on organizational commitment. Job insecurity comprised two constructs of threatening feeling of job loss and powerlessness, which were examined and supported by factor analysis.

Further analyses found that the threatening feeling of job loss in the job insecurity had no significant effect while the powerlessness had a significant negative effect on organizational commitment. 


\section{ORGANIZATIONAL COMMITMENT, JOB INSECURITY}

This study discovered that the powerlessness in the job insecurity played a key role in the negative effect on organizational commitment and job involvement. According to the literature, the powerlessness in the job insecurity is the perceived inability to control negative changes in the work environment.

However, in the work alienation literature, powerlessness was defined as one construct of work alienation, namely that individuals who do not have control in the process of work can only passively accept the unchangeable things. Such a sense of powerlessness may cause employees to force themselves to maintain a formal relationship with the organization or other people, and work is not an end in itself, but only a means to achieve other purposes. The powerlessness hereto was the same feeling of inability to change the current situation as that of job insecurity.

Therefore, when employees have this feeling, they will easily alienate the relationship with the organization and become less enthusiastic about their work, which may lead to the negative result of decreased organizational commitment and job involvement.

The powerlessness had a direct significant negative effect on job involvement and also had an impact on organizational commitment, which further produced an indirect effect on job involvement. The total effect of powerlessness on job involvement was -0.425 while the total effect thereof on organizational commitment was -0.25 , showing that powerlessness had a higher impact on job involvement.

The good operation of an enterprise depends on the dedication of its employees, and to establish a strong relationship with the enterprise is a good method to make employees dedicated to work. Therefore, managers bear the heavy responsibility for creating this relationship. This study showed that job insecurity or its powerlessness can damage the job involvement and relationship with the organization.

Powerlessness had a negative effect on organizational commitment and job involvement, and also further reduced job involvement through organizational commitment. Therefore, managers should prepare management strategies to eliminate the powerlessness of employees in the work. In addition, the entire sense of insecurity (including powerlessness and threat of job loss) reduced job involvement.

Compared with organizational commitment, the most important part of job involvement was the good performance in the work, which had a direct relationship with an employee's output and thus was the basic performance indicator of employees that managers should pay attention to. Besides the powerlessness above, we can try to reanalyze where the threatening feelings of job loss in the organization come from, so that managers can put forward effective management methods to lower the psychological insecurity after inevitable job losses.

The main source of perceived threat of job loss may be the employee's perception that the company pays less attention to him or her, or the employee's anxiety that he or she has to adapt to the new job due to the change of working environment. In addition to the objective factor that causes most employees to have these negative emotions, another important factor may be caused by the lack of confidence of employees in their own abilities.

In this study, due to the high sensitivity of issues related to personal inner thoughts such as job insecurity, time limit and manpower constraints, the participants may not provide their true inner thoughts and feelings. In addition, the sample size is limited by the employees that the researcher can contact with, so the coverage is not broad enough. 
Moreover, the limited sample size will also affect the representativeness of the research results. Anonymity and privacy protection should be considered in subsequent studies, and the scope and number of participants should be expanded, so as to enhance the authenticity and representativeness of the study.

In follow-up studies, it is suggested that the reasons of job insecurity be divided into external environment, internal environment and personal features, etc., so as to discuss the job insecurity issues caused by three different reasons and to explore whether the three categories of job insecurity have different effects on organizational commitment, job involvement and other variables. In this way the results of the study will be more mature and scientific.

\section{References:}

Ashford, S. J., Lee, C. \& Bobko, P. (1989). Content, causes, and consequences of job insecurity: A theory-based measure and substantive test. Academy of Management Journal, 32(4), 803-829.

Borgatta, E. F., Ford, R. N. \& Bohrnstedt, G. W. (1968). The work components study (WCS): A revised set of measures for work motivation. Multivariate Behavioral Research, 3(4), 403-414.

Brave, S. \& Nass, C. (2003). Emotion in human computer interaction. In: Jacko \& Sears (Eds.), The Human Computer Interaction Handbook. Lawrence Erlbaum Associates. Mahwah, NJ.

Clinebell, S. \& Shadwick, G. (2005). The importance of organizational context on employees' attitudes: An examination of working in main offices versus branch offices. Journal of Leadership and Organizational Studies, 11(2), 89-100.

Cooper, C. L., Dewe, P. J. \& O’Driscoll, M. P. (2001). Organizational stress: A review and critique of theory, research and applications. Lexington, KY: D. C. Heath.

Dewitte, H. D. (1989). Job Security and psychological well-being: Review of the literature and exploration of some unresolved issue. European Journal of Work and Organizational Psychology, 8(2), 155-177.

Ellis, A. (1979). Reason and Emotion in Psychotherapy. Secaucus, N.J: Citadel.

Folkman, S. \& Moskowitz, J. T. (2000). Positive affect and the other side of coping. American Psychologist, 55, 647-654.

Fredrickson, B.L. (2002). What good are positive emotions? Review of General Psychology, 2(3), 300-319.

Greenhalgh, L. \& Rosenblatt, Z. (1984). Job insecurity: Toward conceptual clarity. Academy of Management Review, 9, 438-448.

Kanungo, R. N. (1982). Measurement of Job and Work Involvement. Journal of Applied Psychology, 67, 341-350.

Kuhert, K. W. \& Palmer, D. R. (1991). Job security, health and the intrinsic and extrinsic characteristics of work. Group and Organization Studies, 16, 178-192.

Lodahl, T. M. \& Kejner, M. (1965). The definition and measurement of Job involvement. Journal of Applied Psychology, 49(1), 24-33.

Mathieu, J. E. \& Zajac, D. M. (1990). A review and meta-analysis of the antecedents, correlates, and consequences of organizational commitment. PsychologicalBulletin, 20, 709-734. 


\section{ORGANIZATIONAL COMMITMENT, JOB INSECURITY}

Meyer, J. P., Allen, N. J. \& Gellatly, I. R. (1991). Affective and continuance commitment to the organization: Evaluation of measures and analysis of concurrent and time-Legged relations. Journal of Applied Psychology, 75(6), 710-720.

Prashant, E. \& Cindy, V. (2004). Uncertainty during organizational change: types, consequences, and management strategies. Journal of Business and Psychology, 18(4), 507-532.

Rosenblatt, Z. \& Ruvio, A. (1996). A test of multidimensional model of job insecurity: The case of Israeli teachers. Journal of Organizational Behavior, 17(1), 587-605.

Sanghamitra, B. \& Leena, C. (2005) Organizational Downsizing from Concepts to practices, VIKALPA, 30, 65-78.

Steers, R. M. (1977). Antecedents and Outcomes of Organizational Commitment. Administrative Science Quarterly, 22(1), 46-56.

Sverke, M., Hellgren, J. \& Naswall, K. (2002). No security: A meta-analysis and review of job insecurity and its consequences. Journal of Occupational Health Psychology, 7, 242-264.

Paper submitted

Paper accepted for publishing

Paper published online
08 September 2021

16 November 2021

31 January 2022 